\title{
Designing Meaningful Landscapes through Systematic Discovery of Character of Place
}

\author{
Rasoul Rafat ${ }^{1, *}$, Sara Mirhadi ${ }^{2}$ \\ ${ }^{1}$ Department of Landscape Architecture, College of Fine Arts, University of Tehran, Iran \\ ${ }^{2}$ School of Art, Architecture and Design, University of South Australia, Australia
}

Copyright $@ 2017$ by authors, all rights reserved. Authors agree that this article remains permanently open access under the terms of the Creative Commons Attribution License 4.0 International License

\begin{abstract}
Place is a space which takes meanings due to human activities. Perceptions and memories contribute to shape such meanings and especially distinguished character. Character of place as the general atmosphere of the place can increase place attachment which is defined as an emotional bond between place and people and causes vitality, involvement, safety and sense of responsibility. Thus, a space can be turned into a place of with a higher quality by reviving its character. Such places can become a "Landscape". This investigation aims to explore the factors which help to find character of the place. To achieve this purpose, it reviews the theories of place and landscape. It continues with defining and comparing four concepts related to place that are very close in meanings such as genius loci, place identity, essence of place and character of place. Through a major analysis, the factors that could lead us to decode the main character of a place will be extracted. A Questionnaire survey, based on the factors, is used to evaluate and discover the principal character of the place in the context of a case study of Shiraz. Results suggest that inhabitants' memories, which are latent in historical, social and cultural context, determine the genuine character of place and can recreate the missing place attachment in modern landscapes. In conclusion, character of place is a main concept which is contextual and should be discovered through the factors in the study phase in order to design meaningful landscapes.
\end{abstract}

Keywords Place Attachment, Landscape, Character of Place

\section{Introduction}

Nowadays, urban inner development which occurs inattentively in micro scales places causes changing their meanings and values and disappear them under this development to some extent. Each space has specific character which is hidden in its landscape. Urban development and designing spaces without considering place identity could vanish the values of landscape [2]. Designing meaningful places is essential in environmental studies. To achieve these places, specialists should discover the character of a place and identify ways to conserve and embed its character in future development projects. Some specialists use the term of 'character of place' as equal as 'essence of place', 'place identity' and 'sprit of place or genius loci' [12, $14,17-18]$.

Landscape knowledge promotes an understanding of places and projects based on multiple layers of context such as cultural, historical, ecological and etc. It includes people and what they do and have done, in the same frame as a comprehensive view of the natural world. One of the main tasks of landscape architects and urban designers is creating meaningful places with a certain character and the aim of landscape architecture and urbanism is converting a location (site) to a place (landscape). Every context has its character and unique meaning which should be discovered and revealed. As Schulz [16] states, "rediscovery of true characters enables us to make meaningful environments" and Relph [14] accepts human intervention in places would be successful, if the main character of place is recognized. Hence, character of place or basic meaning of place should be discovered and identified.

The assumption of this paper is that recognizing the features of a place and decoding its fundamental character based on layers of context, is a suitable approach to create place attachment which could be reached through contextual factors. Thus, this research aims to extract factors in order to discover the main character of the place. The methods in this research are firstly a review of logical literature and case studies and secondly identifying and extracting affective factors which could be used to decode and reveal the character. Afterwards, the extracted factors were analyzed in a case study by questionnaire survey among its inhabitants. 
Table 1. Factors Expressed in the Definitions of Place and Landscape

\begin{tabular}{|c|l|}
\hline Terms & \multicolumn{1}{c|}{ Factors } \\
\hline Place & $\begin{array}{l}\text { human experience, memories, history, nature, behaviors, activities, meaning, human presence, ongoing, non-fixed, } \\
\text { indeterminate, social essence, plural memories, context, symbols }\end{array}$ \\
\hline Landscape & $\begin{array}{l}\text { human experience, essence of place, interaction, human presence, history, nature, dynamic, ongoing, event, culture, } \\
\text { vernacular, social, memories, activities, plural memories, context }\end{array}$ \\
\hline
\end{tabular}

\subsection{Place}

Place is a physical-spiritual phenomenon which is the outcome of human experience and history. Time and experience are constantly renewed, so that place has an indeterminate and ongoing nature [10]. Place is a vessel which holds memories and memory is place-based. As plural memories have a social essence, their context is the location for social interaction .Schulz [16] claims that perception of the space and its combination with human memories, the outcome of which is "presence" in the space, would create place [16].

Place is a set of connected cultural characteristics which could be a motivator for human experiences and a memorial of cultural concepts and meanings [1]. Canter [4] argues that place is the outcome of the interaction of behavioral factors, perceivable meanings for humans and the physical characteristics of the space or environment [9]. Places provide a blend context of social and physical characteristics. We continuously regenerate places through our mental ability and physics. Winchester [19] points to places as 'social constructions'. She believes that identity of place would be created by different substrates such as physical and symbolic characteristics [19].

\subsection{Landscape}

Landscape is a type of place and the outcome of interaction between humans and the environment in external space [3]. As Mansouri [10] states, landscape is the essence of the place and it does not emerge spontaneously, but forms gradually due to human experience. It is an intermediate area that is formed with human presence. The common tune of history and nature is apparent in landscape [10]. Plurality of space is one of the features forming the urban landscape as a context for creating multiple memories, so a city is a common context for human activities and events [7]. As Cullen [5] assigns, landscape is dynamic and ongoing [5]. The cultural essence should be observed by architects, landscape architects and geographer in the vernacular landscape [8]. Humans interpret their landscapes and cultural meanings as features of the place in their own way Briefly, the spirit of place lies in its landscape [6, 14].

Place is intertwined with many different aspects such as landscape, religion, community, plural memory, residence and context in which all these layers are associated [10]. Therefore, according to the aspects derived from the literature it could be considered that Place and Landscape have similar characteristics and meanings.

\subsection{Place Identity}

According to Relph [14]: The relationship between community and place is indeed a very powerful one in which each reinforces the identity of the other and in which the landscape is very much an expression of communally held beliefs, values and of interpersonal involvements [14]. Ross and Uzzell [18] assert that place identity is not merely a 'separate part of identity' but rather 'all aspects of identity have place related implications'. They focus on the importance of continuity, distinctiveness self-esteem and self-efficacy in the development of place identity [18]. Relph [14] describes this persistent identity in terms of three components: (1) the place's physical setting; (2) its activities, situations, and events; and (3) the individual and group meanings created through people's experiences and intentions in regard to that place.

\subsection{Genius Loci/ Spirit of Place}

The combination of characteristics that gives some locations a special 'feel' or personality (such as a spirit of mystery or of identity with a person or group) [17]. Spirit of place (Genius Loci) is latent in its landscape [12]. At first, Place conditions are reflected in landscape and demonstrate values, meanings, activities and human purposes. Spirit of place would help to practice the environment potentials [14]. Reviving character of place is an approach to achieve spirit of place.

\subsection{Essence of Place}

The basic meaning of place, its essence, does not come from a specific location, the community that occupies it, or superficial and mundane experiences, though all these are common and perhaps necessary aspects of places. The essence of place lies in its role as a profound center of human existence. There is for virtually everyone a deep association with and consciousness of the places where we were born and grew up, where we live now, or where we have had particularly moving experiences. Acceptance of place as multidimensional phenomenon and by analyzing different features of the place such as location, landscape and personal dependence would create essence of place [14].

\subsection{Character of Place}

Place is the resultant of location and features such as history, event, plural memories, which defines character [14]. 
Character of place is general atmosphere and the most important feature of a place. Certain form and essence of elements of space are combined with character. Sense of place is latent with essence of place and it is found in places with certain character. Discovering the meaning of place determines character of place [12]. According to the literature, the character of place refers to the general atmosphere of a place [12]. Schulz classifies character into 3 classes: 1. Natural character; 2. Human character; 3. Mental and emotional character, beliefs and values.

When person resides lives in a place two functions emerge: "orientation" and "identification" which are important factors of character of place. If this happens, sense of place would exist. Humans combine their meanings with physically recognizable places. Changes in character of place are based on the changes in buildings, landscapes and viewpoints and after a long absence; it could make a dramatic difference to someone once familiar with it [14].

\section{2. 'Character of Place', 'Place Identity', 'Essence of Place' and 'Spirit of Place': A Comparison}

'Place Identity', 'Spirit of Place', 'Essence of Place' and 'Character of Place' are dependent to different degrees of factors such as human, social, historical, geographical and indigenous aspects. These terms are almost conceptually equal in meaning regarding the main and vital character of a place.

As it is mentioned in the literature, place identity is a statement of values and people's engagement in the landscape, similarly spirit of place which is a sense of identity to an individual or a collective group, is hidden in its landscape too. In the definition of spirit of place, there is a point to the values and also human activities which is the same as features in place identity. In essence of place, it is defined by basic meaning of place and human existence which are mentioned clearly in defining place identity and spirit of place. Moreover, it is noted that human experiences plays important role in all the descriptions.

As it is assigned that spirit of place could create by restoring character of place. In addition, character of place as the most important feature in the place points to meaning and identity and exploring the principal meaning of the place depends on character of place. The other factor which is notified in 4 concepts is plural memories. Similar to the three concepts, character of place is related to values, human, and beliefs too. Thus, landscape considers as the essence of the place which helps to identify character of landscape.

\subsection{Factors Contributing in Identification of Character of Place}

The most important factors that have influence in forming the character of place has been extracted from literature review and presented in this part with their definitions.

- Orientation and Identification: According to Partoi [12], orientation is identifying about where to be, how other places related to and identification are becoming friend with specific environment.

- History and Time: Time is a part of our experience of places because experiences are based on constant changes and places are expressing them and older events and future hopes [14, 15]. Characters are discovered in time process and due to their discovery; characters are as existential facilities [16].

- Society (beliefs, values, relations): Relationship between society and place is very strong and reinforce each other's identity, beliefs, values and relations [14, 15]. Socialization is main point contributing to promote space to place and creating sense of place, place identity and spirit of place [16].

- Physical Factors: Place is formed with elements such as material, form, texture and color and they define character of environment [14]. Discovery of ecology and geography is important in connection the concept of place to the nature and human order [13].

- $\quad$ Religion, Tradition and Legend: In traditions, legends and religions, the importance of place is sanctity and the lifelong relation between people and place which promote dependence to the place [14].

- Meaning: Each meaning reveals in particular place and character of place depends on this detection [14].

- Nature: Protection of nature means let it to be based on its essence [12]. Nature is a continuous integrity, as being according to the local conditions [16].

- Activity and Function: Maintaining micro- scale and local functions should be a priority. Activity taking place is necessary for converting space to place [16].

- Memory: Places affect our memories through encounter repeatedly and experiences are memory-based [14]. Place is space which is felt, understood and mixed with memories [16].

\section{Research Methods}

\subsection{Study Area; Case Study of Ghodoosi Gharbi Neighborhood, Shiraz}

Ghasrodasht is a region of Shiraz in Iran which used to be a green context with lots of gardens. These local gardens are well known as Ghasrodasht Gardens because of their different texture and design with indigenous trees and plants. To illustrate more, these gardens are shaped due to the natural water paths, thus they are designed organically. One of the most memorable features of these gardens is their traditional clay garden wall which is called 'Chineh' and they are one of the identical elements of these region which formed alleys and these alleys are called 'Koocheh Baghi'. Unfortunately, in recent years, most of these gardens are 
going to disappear and transform to residential buildings like apartments and houses. Ghodoosi Gharbi Neighborhood is one of the neighborhoods in this area which consists of both apartments and old houses and just a few gardens remained after redevelopment (Figure 1).

To explore the main character of landscape, firstly we analyzed all the layers of the neighborhood such as its history, geography, society and meanings, and secondly we have done a questionnaire survey among the neighborhood residents to assess these layers and factors in order to discover the main character of the landscape and develop place attachment.

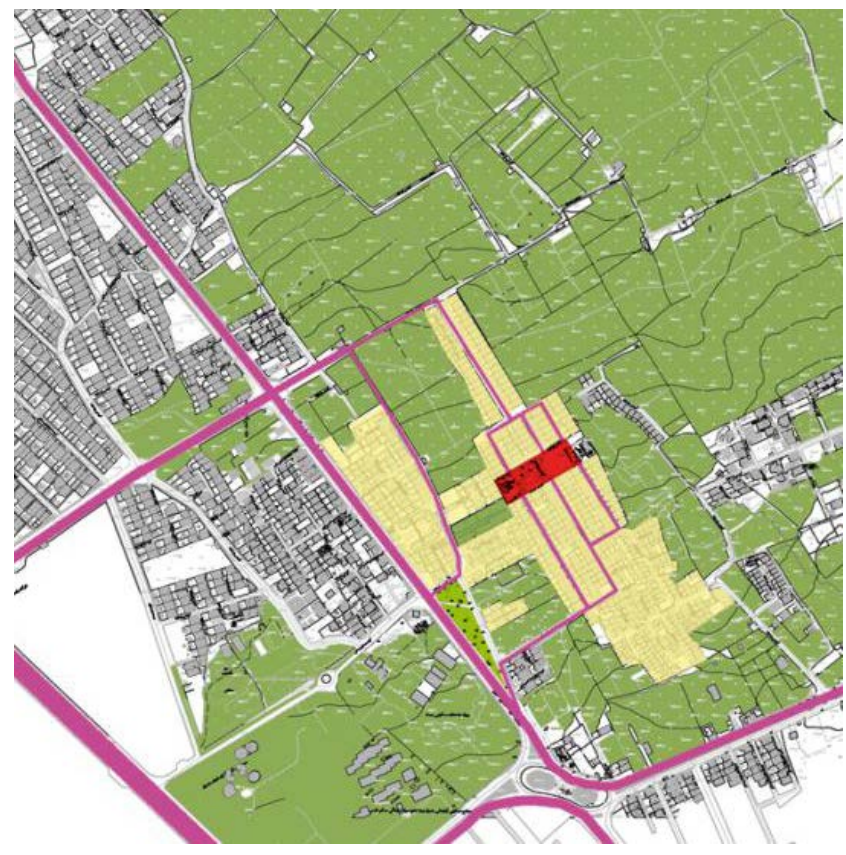

Figure 1. Garden is disappearing with urban residential blocks. The neighborhood centers could be revitalized as a social garden for residents.

\subsection{Survey Instrument}

This study involved a questionnaire survey of Ghodoosi Gharbi Neighborhood based on factors contributing on the identification of character of place. The survey instrument has been done among participants who were 30 local residents of this neighborhood to rate the importance of each factor to recognize the character of neighborhood center. The rating analysis has been done by using 5-point Likert scale. A series of questions asked participants about their memories, perceptions, historical and societal aspects, meanings, activities, the role of traditions and religious events and sense of security.

\section{Results and Discussion}

The results have been presented in table 2. Means of the grades has been shown in the second column. In addition, the results of the rating means have been shown in third column as an 'Analysis based on survey results'.
Table 2. Evaluation of factors contributing to identify character of landscape (by authors)

\begin{tabular}{|c|c|c|c|}
\hline \multicolumn{2}{|c|}{ Factors } & Mean & $\begin{array}{c}\text { Analysis based on } \\
\text { survey results }\end{array}$ \\
\hline \multicolumn{2}{|c|}{ Orientation } & 3.20 & \multirow{2}{*}{ Medium } \\
\hline \multicolumn{2}{|c|}{ Identification } & 3.16 & \\
\hline \multicolumn{2}{|c|}{ History } & 4.70 & \multirow{2}{*}{ Very High } \\
\hline \multicolumn{2}{|c|}{ Time } & 4.86 & \\
\hline \multirow{3}{*}{ Society } & Beliefs & 3.20 & \multirow{3}{*}{ Medium } \\
\hline & Values & 3.40 & \\
\hline & Relations & 3.12 & \\
\hline \multirow{4}{*}{$\begin{array}{l}\text { Physical } \\
\text { Factors }\end{array}$} & Color & 1.23 & \multirow{4}{*}{ Low } \\
\hline & Material & 1.44 & \\
\hline & ecology & 1.08 & \\
\hline & Geography & 1.41 & \\
\hline \multicolumn{2}{|c|}{ Religion } & 4.47 & \multirow{3}{*}{ High } \\
\hline \multicolumn{2}{|c|}{ Tradition } & 4.50 & \\
\hline \multicolumn{2}{|c|}{ Legend } & 4.41 & \\
\hline \multicolumn{2}{|c|}{ Meaning } & 3.13 & Medium \\
\hline \multicolumn{2}{|c|}{ Nature } & 4.41 & High \\
\hline \multicolumn{2}{|c|}{ Activity } & 3.03 & \multirow{2}{*}{ Medium } \\
\hline \multicolumn{2}{|c|}{ Function } & 3.36 & \\
\hline \multicolumn{2}{|c|}{ Memory } & 4.93 & Very High \\
\hline \multicolumn{4}{|c|}{$\begin{array}{l}\text { Scale: } 1-1.99=\text { Very Low; } 2-2.99=\text { Low;3-3.99= Medium; } 4-4.5= \\
\text { High; } 4.5-5=\text { Very High. }\end{array}$} \\
\hline
\end{tabular}

It was clear that factors such as plural memories, history, nature and tradition are the most important ones to emerge and more relevant to the residents of the sampled neighborhood. In the questionnaires, it was frequently mentioned that almost all of the older participants, who have lived there for a long time, recall the memory of the traditional gardens of this area. Similarly, younger residents, who came to live in the area more recently, pointed to the traditional clay garden walls, "Chineh", and alleys, "Kooche Bagh" as the most important meanings to them (figure 2). The research showed that these meanings could be understood as symbols of identity for this neighborhood and the 'garden' is the main characteristic of place for this neighborhood. In consequence, reviving and revitalizing the memory of the traditional garden of Ghasroddasht could be an important task for landscape architects and urban designers.

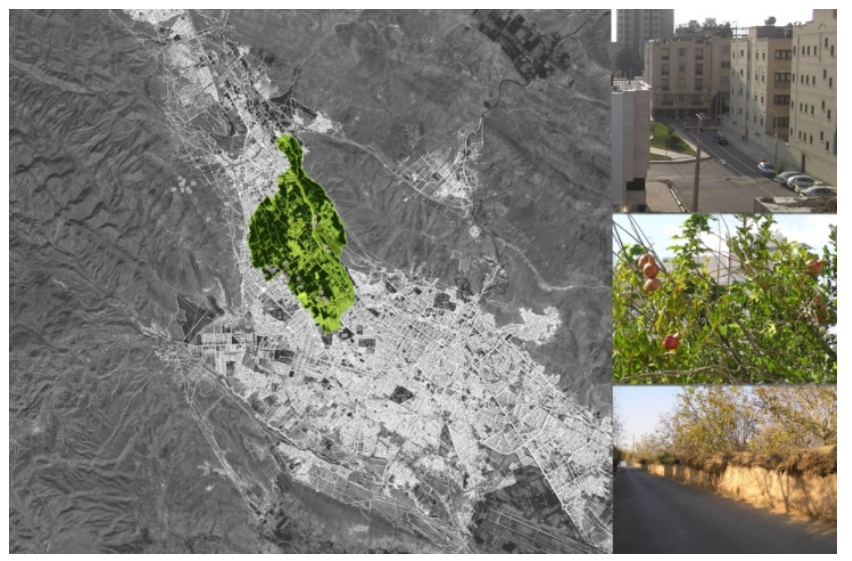

Figure 2. Ghodoosi Gharbi neighborhood, Shiraz; modern apartments, garden and traditional clay garden walls (Chineh) 


\section{Conclusions}

"Place identity", "Genius Loci or Spirit of place”, "Essence of place" and "Character of place" are entwined together and have a common meaning. The most important concept in all of them is character of place which is latent in its landscape. To face with urban and place making projects, it is essential to study deeply to understand different layers of context from physical aspects to mental ones. To explore the main character of places, a wide range of study have to be done and different contextual aspects such as historical, cultural, symbolical, societal and other identifications should be considered in discovering the place identity. Analysis findings and discovering the character of place could have formed the main concept in designing and action plans.

In the results of the case study of this paper, the most important factor to identify as the main character of neighborhood center in neighborhood residents' point of views lies in their history and memory of context. The site was a traditional garden and people are aware of that. Thus, identified features of traditional garden and its memories should be taken in to consideration as a pivotal concept of design for urban landscape designers and place makers.

\section{REFERENCES}

[1] Altman, I. and Setha Low., Place Attachment, Plenum Press, New York. 1992.

[2] Antrop, M., Why landscapes of the past are important for the future. Landscape and urban planning, Vol.70, No.1, 21-34. 2005.

[3] Berque, Augustin. Cinq propositions pour une théorie du paysage, Seyssel, Champ Vallon, Paris, 1994.

[4] Canter, D., The psychology of place. 1977.
[5] Cullen, G., The Concise Townscape, Van Nostrand Reinhold Company, New York. 1972.

[6] Durrell, L., \& Thomas, A. G., Spirit of Place. Marlowe, 1969.

[7] Ghavampour, E., Study on the Relation between Historical Memory of Space and Its Success", MANZAR the Scientific Journal of Landscape, Vol.2, No.11, 76-77, 2010.

[8] Jackson, J. B., Discovering the vernacular landscape, Yale University Press, 1984.

[9] Lang, J., Creating Architectural Theory: The Role of the Behavioral Sciences in Environmental Design, Van Nostrand Reinhold Company, New York, 1987.

[10] Mansouri, S.A., "What is the Urban Landscape", MANZAR the Scientific Journal of Landscape, Vol.2, No. 9, 30-33. 2010.

[11] Norberg-Schulz, C., The phenomenon of place. The Urban Design Reader, 3, 125-137, 1976.

[12] Partoei, P., Place Phenomenology, Academy of Arts of the Islamic Republic of Iran, Tehran, Iran, 2008.

[13] Rapoport, A., The Meaning of the Built Environment: a Nonverbal Communication Approach, The University of Arizona Press, 1990.

[14] Relph, E., Place and Placelessness, Pion, London, 1976.

[15] Relph, E., Senses of place and emerging social and environmental challenges. Sense of place, health and quality of life, 31-44, 2008.

[16] Schulz, N., Genius Loci: Towards a Phenomenology of Architecture, Rizzoli, New York, 1991.

[17] Steele, F., The sense of place. Cbi Pub Co, 1981.

[18] Twigger-Ross, C. L., \& Uzzell, D. L., Place and identity processes. Journal of environmental psychology, Vol.16, No. 3, 205-220, 1996.

[19] Winchester, H. P., McGuirk, P. M., \& Dunn, K. M., Constructing places for the market: the case of Newcastle, NSW. International Journal of Heritage Studies, Vol. 2, No. 1-2, 41-58, 1996. 